(2) Open Access Full Text Article

\title{
Drug utilization in selected health facilities of South West Shoa Zone, Oromia Region, Ethiopia
}

This article was published in the following Dove Press journal:

Drug, Healthcare and Patient Safety

23 July 2015

Number of times this article has been viewed

\author{
Mengistu Kebede \\ Dereje Kebebe Borga \\ Eshetu Mulisa Bobasa \\ Department of Pharmacy, Jimma \\ University, Jimma, Ethiopia
}

Correspondence: Eshetu Mulisa Bobasa Department of Pharmacy, Jimma University, PO Box 378,

Jimma, Oromia, Ethiopia

Tel +25I 93246736 I

Email mulisa2e@yahoo.com
Background: Sustaining the availability and rational use of safe and effective drugs is a major problem in developing countries. Irrational drug use affects quality of health care more than accessibility of drugs.

Objective: To assess drug utilization in selected health facilities of South West Shoa Zone, Oromia Region, Ethiopia.

Methods: A cross-sectional study was conducted in selected health facilities of South West Shoa Zone from January 21-28, 2012 by using structured questionnaires.

Results: Of 50 prescribers and 30 dispensers, $58 \%$ and $83.3 \%$ were males, respectively. The result showed that majority of prescribers agreed on availability of essential drugs (72\%) and had access to up-to-date drug information (76\%). However, $43.3 \%$ of dispensers didn't get access to up-to-date drug information. $86 \%$ and $88 \%$ of prescribers note cost of drugs and stick to standard treatment guidelines of Ethiopia during prescription, respectively. All drug dispensers check the name of the drug $(100 \%)$, age of the patient $(90 \%)$, the dosage form of drug $(96.7 \%)$, the route of administration $(90 \%)$, the duration of therapy $(86.7 \%)$, and frequency of administration (86.7\%) for prescription papers.

Conclusion: In general, drug utilization at the study sites was found to be good, although there are major deviations from the concept of rational drug use.

Keywords: drug utilizations, rational drug use, health facilities

\section{Introduction}

The World Health Organization (WHO) addressed drug utilization as "healthcare provider prescribing, pharmacist dispensing, and patient use of medications considering its consequences; medical, social, and economic impacts." ${ }^{1}$ Thus, the focus of drug utilization is related to factors such as prescribing, dispensing, administering, and taking of medications. "Health providers and pharmacists can only master the prescribing and dispensing of a limited number of drugs. High-quality drug utilization is therefore associated with the use of a relatively limited number of pharmaceutical products". ${ }^{2}$ These important and relevant drugs are called essential medicines. Essential medicines are described as "those that satisfy the priority health care needs of the population. They are selected with due regards to public health relevance, evidence on safety, efficacy, quality and comparative cost-effectiveness. They are intended to be available within the context of functioning health systems at all times in adequate amount and appropriate dosage forms with assured quality." ${ }^{3}$ As a result, delivery of quality health service should be supported with regular availability of essential medicines at an affordable price while ensuring their proper prescription and dispensing to patients. Preparing and using essential medicine list is one of the 12 core 
strategies adopted by WHO to control the appropriate use of medicines. ${ }^{4}$ Even though the concept of essential medicine list was introduced in 1985 to Ethiopia, there are still irrational uses of drugs, which is further complicated by medicines shortage and low budget. ${ }^{5}$

The prescriber, the dispenser, the patient (client), the health care system, and pharmaceutical institutions are the major role players in the use of drugs. ${ }^{6}$ In particular, prescribers and dispensers should provide patients clear information so as to maximize therapeutic effect and prevent adverse consequences during therapy. ${ }^{5}$ Inappropriate utilization of medicines is more common in developing countries as there are lack of well trained health professionals along with their attitude and belief towards rational drug use. Such practices are one of the major factors contributing for wastage of scarce financial resources for health. ${ }^{7}$ In Ethiopia, irrational use of medicines is common in health facilities and the patient. ${ }^{5}$ Therefore, the aim of this study was to assess the views of health professionals concerning the utilization of drugs in health facilities and retail drug outlets of South West Shoa Zone, Oromia Region, Ethiopia.

\section{Methods}

The data was collected between January 21 and 28, 2012 from prescribers and dispensers of selected health facilities in South West Shoa Zone. The zone has 2 hospitals, 47 health centers, 38 medium and small clinics, 268 health posts, 2 pharmacies, 8 rural drug vendors, and 16 drug stores. The two hospitals have four pharmacies, namely, inpatient, outpatient, antiretroviral therapy, and store pharmacy, and the health centers have outpatient, antiretroviral therapy (some), and store pharmacy. Simple, random sampling technique using lottery method was used to select the health facilities from each category. The study area sites were Tulu Bollo Hospital, Tulu Bollo Health Center, Woliso Health Center, Harbu Chululie Health Center, some private clinics, all pharmacies of the selected government health facilities, drug stores, and rural drug vendors.

A cross-sectional study was carried out using structured questionnaires consisting of open- and close-ended questions to collect the information on sociodemographic characteristics and drug utilization from prescribers and dispensers. After reviewing the literature, well-structured data collection forms were developed to make the language more clear. The data-collection forms were further developed after pretesting was done in a small portion of dispensers and prescribers (two or three) before the beginning of the data collection. All prescribers and dispensers working in selected hospitals, health centers, pharmacies, clinics, drug stores, and rural drug venders in South West Shoa Zone were our source populations. Those that were present at the time of data collection filled self-administered questionnaires concerning age, sex, occupational status, availability of essential drugs, accessibility of up-to-date drug related information, proper delivery of drugs, adequacy of label on dispensed drugs, and availability of standard treatment guidelines, formularies, and essential drug lists. The variables were selected based on rational drug use studies, ${ }^{5-7}$ and by using key interventions mentioned by the WHO to promote rational drug use. ${ }^{4}$ The principal investigator supervised closely the filling of the questionnaires by dispensers and prescribers. The collected data was fed to SPSS 16 and presented using tables and figures.

The ethical research committe of the pharmacy department, College of Public Health and Medical Sciences, Jimma University approved the study. Then, written informed consent was prepared for approval by review board, and approval was secured. Finally, officials at different levels in the selected health facilities (Tulu Bollo Hospital, Tulu Bollo Health Center, Woliso Health Center, Harbu Chululie Health Center, some private clinics, all pharmacies of the selected government health facilities, drug stores, and rural drug vendors) were contacted and letters of permission were presented. After the purpose of the study was explained, the participants gave their written informed consent to fill selfadministered questionnaires. Confidentiality of the information was assured, privacy was maintained, and the record was filed in the document.

\section{Results}

The questionnaires were distributed to 50 prescribers and 30 dispensers to assess drug utilization practices. Of 50 prescribers, 29 (58\%) were males and $21(42 \%)$ were females. Of them, 7 (14\%), 19 (38\%), 6 (12\%), 17 (34\%), and 2\% were general practitioners, health officers, Bachelor of Science nurses, diploma nurses, and dentist, respectively. Pharmacists, druggists, and pharmacy technicians comprised $33.3 \%, 50 \%$, and $16.7 \%$, respectively, as shown in Table 1.

Drug utilization assessment from prescribers' side showed that $72 \%, 76 \%, 86 \%$ and $88 \%$ of prescribers confirmed availability of essential drugs, had access to up-to-date information, checked the price of drugs, and followed standard treatment guidelines of Ethiopia, respectively. Only 56\% of prescribers' believed in the success of treatment. While prescribing, only $46 \%$ agreed on the equality of local and import medicine (Table 2). 
Table I Sociodemographic characteristics of prescribers $(n=50)$ and dispensers $(n=30)$, January 2012

\begin{tabular}{|c|c|c|}
\hline & $\frac{\text { Prescribers }}{\mathrm{n}(\%)}$ & $\frac{\text { Dispensers }}{\mathrm{n}(\%)}$ \\
\hline \multicolumn{3}{|l|}{ Sex } \\
\hline Male & $29(58)$ & $25(83.3)$ \\
\hline Female & $21(42)$ & $5(16.7)$ \\
\hline Total & $50(100)$ & $30(100)$ \\
\hline \multicolumn{3}{|l|}{ Age } \\
\hline$<25$ & $15(30)$ & $4(13.3)$ \\
\hline $25-34$ & $29(58)$ & $21(70)$ \\
\hline $35-44$ & $5(10)$ & $3(10)$ \\
\hline $45-54$ & I (2) & $2(6.7)$ \\
\hline$>55$ & 0 & 0 \\
\hline Total & $50(100)$ & $30(100)$ \\
\hline \multicolumn{3}{|l|}{ Qualification } \\
\hline General practitioner & $7(14)$ & \\
\hline Dentistry & $\mathrm{I}(\mathrm{I})$ & \\
\hline Health officers & $19(38)$ & \\
\hline BSc nurses & $6(12)$ & \\
\hline Diploma nurses & $17(34)$ & \\
\hline Pharmacist & & $10(33.3)$ \\
\hline Druggist technician & & $15(50)$ \\
\hline Pharmacy technician & & $5(16.7)$ \\
\hline Total & $50(100)$ & $30(100)$ \\
\hline
\end{tabular}

Abbreviation: BSc, Bachelor of Science.

The majority of the prescribers adhere toward correct prescription writing format as evidenced by most of them always prescribing by the generic name (70\%), writing the dosage form $(86 \%)$, writing the age of patients (88\%), duration of therapy (90\%), frequency of administrations (90\%), and considering the therapeutic appropriateness of the indication (66\%). However, only $40 \%, 38 \%$, and $46 \%$ of the prescribers always checked drug availability, drug interaction, and other health information, respectively (Table 3 ).

The response of dispensers to the drug utilization questionnaires indicated that $56.7 \%$ of them get up-to date drug information and $42.5 \%$ search for new information on drugs after drugs are being marketed (Table 4). Majority of the dispensers got drug information from inserted leaflets, drug formularies, standard treatment guidelines, and books (pharmacology and pharmacotherapy).

With respect to checking correct prescription-writing format, majority of dispensers reported that they always check the name $(100 \%)$, the age of the patients $(90 \%)$, the dosage form (96.7\%), the route of administration (90\%), the duration (86.7\%), and frequency of administration (86.7\%) while dispensing prescriptions. $73.3 \%$ of the dispensers always check the availability of drug in health facility. A significant number of dispensers (56.7\%), didn't always explain how to properly store medicines to their patient,
Table 2 Prescribers information related to drugs $(n=50)$, January 2012

\begin{tabular}{|c|c|c|}
\hline Answer & Number & $\%$ \\
\hline \multicolumn{3}{|l|}{ Are essential drugs available? } \\
\hline Yes & 36 & 72 \\
\hline No & 14 & 28 \\
\hline Total & 50 & 100 \\
\hline \multicolumn{3}{|c|}{ Reasons for lack of availability of essential drug } \\
\hline Lack of budget & 8 & 57.1 \\
\hline Lack of responsible professional & 4 & 28.6 \\
\hline Lack of awareness & 2 & 14.3 \\
\hline \multicolumn{3}{|c|}{ Do you get up-to-date drug information? } \\
\hline Yes & 38 & 76 \\
\hline No & 12 & 24 \\
\hline Total & 50 & 100 \\
\hline \multicolumn{3}{|c|}{ Do you stick to standard treatment guidelines of Ethiopia? } \\
\hline Yes & 44 & 88 \\
\hline No & 6 & 12 \\
\hline Total & 50 & 100 \\
\hline \multicolumn{3}{|c|}{ Do you take note of drugs' price before prescribing? } \\
\hline Yes & 43 & 86 \\
\hline No & 7 & 14 \\
\hline Total & 50 & 100 \\
\hline \multicolumn{3}{|c|}{ How do you rate adherence of patients to drugs? } \\
\hline Very good & 11 & 22 \\
\hline Good & 24 & 48 \\
\hline Moderate & 15 & 30 \\
\hline Total & 50 & 100 \\
\hline \multicolumn{3}{|c|}{ What do you think is the possibility of success in treatment? } \\
\hline$>75 \%$ of patients & 28 & 56 \\
\hline $50 \%-74 \%$ of patients & 22 & 44 \\
\hline Total & 50 & 100 \\
\hline \multicolumn{3}{|c|}{ Which drug/s do you prefer during prescribing? } \\
\hline Local & 14 & 28 \\
\hline Imported & 13 & 26 \\
\hline Both & 23 & 46 \\
\hline Total & 50 & 100 \\
\hline
\end{tabular}

despite $53.3 \%$ report of always checking of drug interaction during dispensing (Table 5).

While communicating to the patients, most of dispensers label the medication appropriately (frequency [93.3\%], route [90\%], quantity [90\%], duration [66.7\%] and use of symbol [70\%]) (Table 6).

\section{Discussion}

Irrational use of pharmaceuticals is commonly observed in health care systems throughout the world, especially in developing countries. This problem can be solved by making essential drugs available, increasing up-to date drug information, and providing an efficient supply of drugs. ${ }^{8}$

The present study focused on drug utilization pattern of prescribers and dispensers. The responses of the majority of prescribers during the study confirmed availability of essential drugs, access to get up-to date information, consideration 
Table 3 Prescribers' correct prescription writing format $(n=50)$, January 2012

\begin{tabular}{|c|c|c|c|c|c|c|c|c|}
\hline \multirow[t]{2}{*}{ Variables } & \multicolumn{2}{|c|}{ Always } & \multicolumn{2}{|c|}{ Often } & \multicolumn{2}{|c|}{$\begin{array}{l}\text { Sometimes } \\
\text { (when needed) }\end{array}$} & \multicolumn{2}{|c|}{ Never } \\
\hline & $\mathbf{n}$ & $\%$ & $\mathbf{n}$ & $\%$ & $\mathbf{n}$ & $\%$ & $\mathbf{n}$ & $\%$ \\
\hline Generic name & 35 & 70 & 14 & 28 & I & 2 & 0 & 0 \\
\hline Dosage form & 43 & 86 & 5 & 10 & I & 2 & I & 2 \\
\hline Age of the patient & 44 & 88 & 5 & 10 & I & 2 & 0 & 0 \\
\hline Duration & 45 & 90 & 4 & 8 & I & 2 & 0 & 0 \\
\hline Frequency & 45 & 90 & 3 & 6 & 2 & 4 & 0 & 0 \\
\hline Availability & 20 & 40 & 16 & 32 & 13 & 26 & I & 2 \\
\hline Appropriateness of the indication & 33 & 66 & 10 & 20 & 6 & 12 & I & 2 \\
\hline Drug interactions & 19 & 38 & 14 & 28 & 16 & 32 & I & 2 \\
\hline $\begin{array}{l}\text { Other patient related problems eg, renal } \\
\text { failure, hepatic failure, etc }\end{array}$ & 23 & 46 & 12 & 24 & 13 & 26 & 2 & 4 \\
\hline Previous medication of the patients & 24 & 48 & 12 & 24 & II & 22 & 3 & 6 \\
\hline
\end{tabular}

of the price of drugs during prescription, and following of standard treatment guidelines of Ethiopia during prescription. But $48 \%$ of them feel good for compliance while little more than half had a belief that more than $75 \%$ of patients can be cured upon treatment. Of importance is that less than $50 \%$ of prescribers believed that there was no difference between locally manufactured and imported drugs.

In a given health care system, there are four major areas related to drug management: rational use, affordable price, sustainable financing, and reliable health and supply systems. In addition, there should be a dynamic and sustainable pharmacovigilance system. Pharmacovigilance is the science of adverse reaction reporting and monitoring medicines safety. It is very important to ensure safety of medicines from their development to their use in large populations. ${ }^{9}$ In other words,

Table 4 Response of dispensers to the questionnaire, January 2012

\begin{tabular}{|c|c|c|}
\hline Response & Number & $\%$ \\
\hline \multicolumn{3}{|c|}{ Do you get access to up-to-date drug information $(n=30)$ ? } \\
\hline - Yes & 17 & 56.7 \\
\hline - No & 13 & 43.3 \\
\hline \multicolumn{3}{|l|}{ What are your source/s of drug information $(n=91)$ ? } \\
\hline - Inserted leaflets & 28 & 30.8 \\
\hline - Books (pharmacology and pharmacotherapy) & 18 & 19.8 \\
\hline - Formularies and standard treatment guidelines & 27 & 29.8 \\
\hline - Bulletins & 13 & 14.3 \\
\hline - Internet & 5 & 5.5 \\
\hline \multicolumn{3}{|l|}{ How do you get new information on drugs $(n=40)$ ? } \\
\hline - After invented (discovered) & 3 & 7.5 \\
\hline - After being marketed & 17 & 42.5 \\
\hline $\begin{array}{l}\text { - Reading materials as the drugs brought to } \\
\text { dispensary room }\end{array}$ & 10 & 25 \\
\hline $\begin{array}{l}\text { - During addition and deletion from essential drug } \\
\text { list }\end{array}$ & 7 & 17.5 \\
\hline - No search for information & 3 & 7.5 \\
\hline
\end{tabular}

rational drug use means "prescribing right drug, in adequate dose for the sufficient duration and appropriate to the clinical needs of the patient at lowest cost." This can be met if the process of prescribing and dispensing is appropriately followed. But a number of factors may be involved in the rational use of medicines. Despite all the challenges, our study site prescribers do have better performance in drug management by following the country essential drug lists and standard treatment guidelines. They also got up to date information. Essential drugs offer a cost-effective solution to many health problems in a developing country. Prescribers can treat patients efficiently if they have access to essential drugs lists and standard treatment guidelines..$^{10,11}$

The major gap identified at the study sites was that the prescribers believed in adherence, which was $48 \%$ good. Adherence is a key determinant in rational drug use, even though drugs were prescribed and dispensed appropriately. The prescribers who responded were also less sure of whether the treatment was successful or not. During management, we have to make wise and evidence-based decisions unless the situation is difficult. ${ }^{12,13}$ Otherwise medication errors may increase morbidity, mortality, health care resource wastage, and adverse drug events. ${ }^{14}$ Even though the majority (70\%) of the prescribers always prescribe by generic name, the requirement by $\mathrm{WHO}$ for rational drug use is always $100 \%$ prescription by generic name. ${ }^{15}$ Prescription by generic name will save the cost incurred by unnecessary brand prescription except in some drugs for which particular attention of concentrations or other factors are needed. ${ }^{16}$

The poor activity of the prescribers is due to their ignorance of previous medications taken by the patients (only $48 \%$ always consider previous medication), drug interactions during prescribing (only $38 \%$ always consider drug interaction), and other patient-related problems (only 
Table 5 Dispensers' checking the correct prescription writing format while dispensing ( $n=30)$, January 2012

\begin{tabular}{|c|c|c|c|c|c|c|c|c|}
\hline \multirow[t]{2}{*}{ Variables } & \multicolumn{2}{|l|}{ Always } & \multicolumn{2}{|l|}{ Often } & \multicolumn{2}{|c|}{$\begin{array}{l}\text { Sometimes } \\
\text { (when needed) }\end{array}$} & \multicolumn{2}{|l|}{ Never } \\
\hline & Number & $\%$ & Number & $\%$ & Number & $\%$ & Number & $\%$ \\
\hline Name of drug(s) & 30 & 100 & - & - & - & - & - & - \\
\hline Age of the patient & 27 & 90 & 1 & 3.3 & I & 3.3 & 1 & 3.3 \\
\hline Dosage form & 29 & 96.7 & 1 & 3.3 & - & - & - & - \\
\hline RDA & 27 & 90 & 1 & 3.3 & 2 & 6.7 & - & - \\
\hline Duration & 26 & 86.7 & 2 & 6.7 & 2 & 6.7 & - & - \\
\hline FoA & 26 & 86.7 & 2 & 6.7 & 2 & 6.7 & - & - \\
\hline ADHF & 22 & 73.3 & 66 & 20 & 2 & 6.7 & - & - \\
\hline TAPD & 15 & 50 & 4 & 13.3 & 11 & 36.7 & - & - \\
\hline Drug interactions & 16 & 53.3 & 7 & 23.3 & 6 & 20 & 1 & 3.3 \\
\hline TPS & 13 & 43.3 & 8 & 26.7 & 7 & 23.3 & 2 & 6.7 \\
\hline
\end{tabular}

Abbreviations: RDA, route of drug administrations; FoA, frequency of administration; ADHF, availability of drug in the health facility; TAPD, therapeutic appropriateness of the prescribed drugs; TPS, telling the proper storage condition to the patient.

$46 \%$ always consider other patient related problems such as renal failure, hepatic failure, etc). These are the most important and most critical factors in deciding what to prescribe, when to prescribe, and what to expect after prescribing. As can be clearly understood from our study, $66 \%$ of the prescribers always consider the therapeutic appropriateness of the indication, but majority lack the knowledge of what appropriate means in pharmacotherapy. It involves not only indication but also consideration of previous medications, drug interactions, and other related complications. ${ }^{17}$

With regard to dispensers, only $56.7 \%$ got up-to-date access. To fill their knowledge gap 42.5\% accessed new information after the drugs were being marketed. Inserted leaflets, national drug formularies, standard treatment guideline of Ethiopia, and books (pharmacology and pharmacotherapy) were their sources of information. The source of information for the dispensers is almost similar to the source of information mentioned by drug dispensers in Mekele town. ${ }^{18}$ The fact that majority of dispensers (30.8\%) use inserted leaflets proved the lack of a source of information

Table 6 Dispensers' communication to the patient $(n=30)$, January 2012

\begin{tabular}{|c|c|c|c|c|}
\hline \multirow[t]{3}{*}{ Labeling parameters } & \multicolumn{4}{|l|}{ Remarks } \\
\hline & \multicolumn{2}{|l|}{ Yes } & \multicolumn{2}{|l|}{ No } \\
\hline & Number & $\%$ & Number & $\%$ \\
\hline Patient's name & 8 & 26.7 & 22 & 73.3 \\
\hline Duration & 20 & 66.7 & 10 & 33.3 \\
\hline Route & 27 & 90 & 3 & 10 \\
\hline Date & 12 & 40 & 18 & 60 \\
\hline Frequency of administration & 28 & 93.3 & 2 & 6.7 \\
\hline Quantity to be dispensed & 27 & 90 & 3 & 10 \\
\hline $\begin{array}{l}\text { Use symbolic in case of } \\
\text { illiteracy }\end{array}$ & 21 & 70 & 9 & 30 \\
\hline
\end{tabular}

for dispensers. WHO promotes use of drug information bulletins rather than leaflets as the latter may contain advertising information rather than real information, except the approved leaflets registered by the regulatory authority of the manufacturer, which carry the real information. ${ }^{18}$ Moreover, unlike prescribers, $43.3 \%$ of dispensers had no access to up-to-date drug information.

Majority of the dispensers always checked the prescription paper for inclusion of names, age, dosage form of drugs, route of administration, duration of therapy, and frequency of administration. But, less than half of them told the patient about proper storage, and almost half always checked drug interactions during dispensing. Patients, health professionals, and the general public have the right to be given adequate explanations about drugs by dispensers due to constantly new drugs entering the market and so its important that information is kept up-to-date. This description should cover any special instructions such as taking the medicine with food or water. In addition, the label should include storage instructions. ${ }^{18,19}$

The study also showed that dispensers give special attention to pregnant women and children, especially since physiological changes during pregnancy may compromise pharmacotherapy. Such physiologic changes include

Table 7 Dispensers focus to special patients $(n=30)$, January 2012

\begin{tabular}{llllll}
\hline Special population & \multicolumn{2}{l}{ Yes } & & No \\
\cline { 2 - 3 } & Number & $\%$ & & Number & $\%$ \\
\hline Pregnant women & 28 & 93.3 & & 2 & 6.7 \\
Children & 27 & 90 & & 3 & 10 \\
Eye or ear problem & 26 & 86.7 & & 4 & 13.3 \\
Elderly patients & 24 & 80 & & 6 & 20 \\
Polypharmacy & 23 & 76.7 & 7 & 23.3 \\
\hline
\end{tabular}


Table 8 Dispensers' response regarding the availability of prescribed drugs (medicine) in the pharmacy and how they control expired dates, January 2012

\begin{tabular}{lcc}
\hline Parameter & Number & $\%$ \\
\hline Check drugs availability at pharmacy has not expired & \\
- Yes & 30 & 100 \\
- No & 0 & 0 \\
Means of checking for expired drugs & \\
- LIFO & 2 & 5.4 \\
- FIFO & 9 & 24.3 \\
- FEFO & 26 & 70.3 \\
\hline Abbreviations: LIFO, last in, first out; FIFO, first-in, first-out; FEFO, first expired, \\
first out.
\end{tabular}

changes in enzyme activity, increment in blood volume, and increased renal output causing general changes in pharmacokinetics of drugs. In addition, drugs may affect the fetus. Therefore, dispensers' consideration of pregnancy during dispensing is supportive for our countries millennium development goal which stated zero mother's death during pregnancy. ${ }^{20}$

\section{Conclusion}

In general, drug utilization of the prescribers was found to be good. Majority of the prescribers were aware of essential drugs and had access to up-to date drug information. They also considered price, followed standard treatment guidelines, used generic names, always considered the therapeutic appropriateness of the indication, and used drug formularies as the source of their information during prescribing. However, majority of the prescribers paid less attention to patient compliance, did not always consider availability of drugs, did not always look at appropriateness, drug interactions, and other related patient problems. Their belief on success of treatment was also not satisfactory. Half of the dispensers got up-to-date drug information, even though this value is lower than that of the prescribers. Majority of the dispensers got drug information from inserted leaflets, drug formularies, standard treatment guidelines, and books (pharmacology and pharmacotherapy). Also, majority of dispensers checked for correctness of prescription and communicated with patients appropriately. Drug utilization is a very complex and multifactorial process. As a result, the study-site drug utilization patterns did not meet the standards of the WHO. However, this can be achieved by involving stakeholders like health science departments, Ministry of Health, Food, Medicine and Healthcare Administration and Control Authority of Ethiopia (FMHACA), pharmaceutical manufacturers and distributors, non-governmental organizations, health profession councils and associations, and all health professionals in the rational use of medicines.

Therefore, we recommend the following points:

- Training should be arranged for both dispensers and prescribers in order to enhance their skill in dispensing and prescribing.

- There should be awareness of all levels of drug utilization with respect to the global concern of antimicrobial resistance going through all levels from the drug manufacturer through to the patient.

- Information should be disseminated to the public about the importance of compliance with treatment regimens, especially within the context of the global problem of antimicrobial resistance.

- There should be establishment of dynamic pharmacovigilance, with respect to the reporting and acting upon adverse drug reactions that also include failure or lack of efficacy of drugs.

- Essential drugs use, their supply, and currently evolving findings on them should be conveyed to the students at tertiary levels through pharmacology course and established drug and therapeutic committees.

- Essential drugs should be available in health centers and hospitals.

- Further research should be done nationally to explore rational use of drugs in Ethiopia.

\section{Disclosure}

The authors report no conflicts of interest in this work.

\section{References}

1. Gama H. Drug utilization studies. Arquivos De Medicina. 2008;22(2/3): 69-74.

2. Bergman U, Popa C, Tomson Y, et al. Drug utilization $90 \%$ - a simple method for assessing the quality of drug prescribing. Eur $J$ Clin Pharmacol. 1998;54:113-118.

3. Food, Medicine and Healthcare Administration and Control Authority of Ethiopia (FMHACA). List of Essential Medicines for Ethiopia. 4th ed. Addis Ababa, Ethiopia: Food, Medicine and Healthcare Administration and Control Authority of Ethiopia; 2010.

4. Saeed KMH, Nasar N, Batoo S, Ghauri R, Rauf A. A description of medication decision-making, dispensing, and utilization for hypertensive patients in Nishtar Hospital Multan, Pakistan. Innovat Pharm. 2013;4(4):134.

5. Abula T, Ashagrie G. Assessment of drug utilization from dispensers and prescribers perspectives. Ethiop J Health Dev. 2003;3:231-237.

6. Adebayo ET, Hussain NA. Pattern of prescription drug use in Nigerian army hospitals. Ann African Med. 2010;9(3):152-158.

7. Afriyie DK, Tetteh R. A description of the pattern of rational drug use in Ghana Police Hospital. Int J Pharm Pharmacol. 2014;3(1):143-148.

8. Furu K. Drug utilization in a public health perspective: establishing a national prescription register in Norway. Norweg J Epidemiol. 2001; 11(1):55-60. 
9. Food Medicine and Healthcare Administration and Control Authority of Ethiopia (FMHACA). Adverse drug event monitoring system, Pharmacovigilance Training Manual for health teaching institutions: participant's guide. Addis Ababa, Ethiopia: FMHACA; 2011.

10. Karande S, Sankhe P, Kulkarni M. Patterns of prescription and drug dispensing. Indian J Pediatr. 2005;72:117-121.

11. State Institute of Health and Family Welfare (SIHFW). Reading Material on Drug Store Management and Rational Drug Use for Medical Officers, Nurses and Pharmacists. Rajasthan, India: State Institute of Health and Family Welfare; 2010.

12. Chiquette E, Posey LM. Evidence-based medicine. In: Dipiro JT, Talbert RL, Yee GC, Matzke GR, Wells BG, Posey LM, editors. Pharmacotherapy: A Pathophysiologic Approach. 7th ed. New York, NY: The McGraw-Hill Companies; 2008.

13. Celik E, Encan MN, Clark MP. Factors affecting rational drug use (RDU), compliance and wastage. Turk J Pharm Sci. 2013;10(1):15-170.

14. Page RL, Linnebur SA, Bryant LL, Ruscin JM. Inappropriate prescribing in the hospitalized elderly patient: defining the problem, evaluation tools, and possible solutions. Clin Interv Aging. 2010;5:75-87.
15. Desalegn AA. Assessment of drug use pattern using WHO prescribing indicators at Hawassa University teaching and referral hospital, south Ethiopia: a cross-sectional study. BMC Health Serv Res. 2013;13:170.

16. Toklu HZ, Dülger GA, Hidıroğlu S, et al. Knowledge and attitudes of the pharmacists, prescribers and patients towards generic drug use in Istanbul, Turkey. Pharm Pract. 2012;10(4):199-206.

17. Lehne RA. Pharmacology for Nursing Care. 7th ed. St Louis, MO: Elsevier; 2010.

18. Ayalew E, Seid Y, Agalu A. Knowledge, attitude and practice of patient medication counseling among drug dispensers in Mekele town, Northern Ethiopia. Int Res J Pharm Pharmacol. 2014;4(2):28-34.

19. Drug labeling forum. Free Health Encyclopedia: Decongestants to Echocardiography, Geneva; 1999.

20. Bertis B. Drugs and Pregnancy: A Handbook. New York, NY: Oxford University Press Inc.; 2006.
Drug, Healthcare and Patient Safety

\section{Publish your work in this journal}

Drug, Healthcare and Patient Safety is an international, peer-reviewed open-access journal exploring patient safety issues in the healthcare continuum from diagnostic and screening interventions through to treatment, drug therapy and surgery. The journal is characterized by the rapid reporting of reviews, original research, clinical, epidemiological and

\section{Dovepress}

post-marketing surveillance studies, risk management, health literacy and educational programs across all areas of healthcare delivery. The manuscript management system is completely online and includes a very quick and fair peer-review system. Visit http://www.dovepress.com/ testimonials.php to read real quotes from published authors.

Submit your manuscript here: http://www.dovepress.com/drug-healthcare-and-patient-safety-journal 